\title{
Argumentação no ensino médio a partir da experimentação investigativa em Química
}

\author{
Argumentation in high school from inquiry-based experimentation in Chemistry \\ Argumentación en la escuela secundaria basada en la experimentación investigadora en Química
}

Recebido: 18/11/2021 | Revisado: 26/11/2021 | Aceito: 29/11/2021 | Publicado: 10/12/2021

\author{
Rodrigo Rozado Leal \\ ORCID: https://orcid.org/0000-0002-1708-5325 \\ Universidade Federal de Santa Maria, Brasil \\ E-mail: rodrigo.leal@ufsm.br \\ Maria Rosa Chitolina Schetinger \\ ORCID: https://orcid.org/0000-0002-5240-8935 \\ Universidade Federal de Santa Maria, Brasil \\ E-mail: mariachitolina@gmail.com
}

\begin{abstract}
Resumo
A pesquisa em educação em ciências vem recomendando atenção às práticas argumentativas. $\mathrm{O}$ desafio é buscar atividades que estimulem esse tipo de prática para que os alunos falem ciência, pois isso é considerado benéfico à compreensão conceitual e proporciona aos alunos a capacidade de pensar criticamente em um contexto científico. Neste artigo, é discutido como 20 atividades com experimentos investigativos em química podem promover a argumentação em alunos do ensino médio no laboratório de química. Esse tipo de abordagem experimental oferece aos alunos a oportunidade de aprender e apreciar o processo da ciência. As atividades foram categorizadas de acordo com o nível de proximidade à uma atividade investigativa e também com seu grau de abertura. Os discursos durante as atividades foram analisados a fim de identificar argumentos, segundo o padrão de argumentação de Toulmin. $\mathrm{O}$ estudo mostrou que a experimentação investigativa pode ser uma plataforma eficaz para estimular a produção de argumentos. Atividades com maior nível de investigação e abertura tiveram um impacto maior na produção de argumentos, especialmente os mais ricos, de acordo com a ferramenta de análise escolhida no estudo.
\end{abstract}

Palavras-chave: Experimentação Investigativa; Argumentação; Ensino Médio; Ensino de Química.

\begin{abstract}
Research in Science Education has been recommending attention to argumentative practices. The challenge is to look for activities that can stimulate this type of practice so that the students talk science, since it is considered to be beneficial to conceptual understanding and provide students with the ability to think critically in a scientific context. In this paper, it is discussed how 20 activities with inquiry-type experiments in chemistry can promote argumentation in high school students in the chemistry laboratory. This kind of experimentation approach give the students the opportunity to learn and appreciate the process of science. The activities were categorized according to the level of proximity to an investigative activity and also their degree of openness. The discourses during the activities were analyzed in order to identify arguments, according to Toulmin's argument pattern. The study showed that inquiry experimentation can be an effective platform to stimulate the production of arguments. Activities with a higher level of inquiry and openness had a greater impact on the production of arguments, especially those richer, according to the analysis tool chosen in the study.
\end{abstract}

Keywords: Inquiry Experimentation; Argumentation; High School; Teaching Chemistry.

\begin{abstract}
Resumen
La investigación en educación científica ha estado recomendando atención a las prácticas argumentativas. El desafío es buscar actividades que incentiven este tipo de práctica para que los estudiantes hablen ciencia, ya que se considera beneficiosa para la comprensión conceptual y brinda a los estudiantes la capacidad de pensar críticamente en un contexto científico. En este artículo se discute cómo 20 actividades con experimentos de investigación en química pueden promover la argumentación en estudiantes de secundaria en el laboratorio de química. Este tipo de enfoque experimental brinda a los estudiantes la oportunidad de aprender y apreciar el proceso de la ciencia. Las actividades se categorizaron según el nivel de proximidad a una actividad de investigación y también su grado de apertura. Los discursos durante las actividades fueron analizados con el fin de identificar argumentos, de acuerdo con el patrón de argumentación de Toulmin. El estudio mostró que la experimentación investigativa puede ser una plataforma eficaz para estimular la producción de argumentos. Las actividades con mayor nivel de investigación y apertura tuvieron un mayor impacto en la producción de argumentos, especialmente los más ricos, según la herramienta de análisis elegida en el estudio.
\end{abstract}

Palabras clave: Experimentación investigativa; Argumentación; Escuela secundaria; Enseñanza de la química. 


\section{Introdução}

A educação básica brasileira está passando por uma transição importante, com a implementação da Base Nacional Comum Curricular (BNCC), que estabelece um conjunto de "aprendizagens essenciais" que todos os estudantes brasileiros devem desenvolver ao longo das etapas da educação básica. Tal proposta visa um trabalho que não ofereça somente conteúdos curriculares ou conceitos específicos dentro de disciplinas, mas um trabalho com variadas habilidades e competências, como a argumentação, que é abordada neste relato (Brasil, 2018).

Na BNCC, a argumentação aparece explicitamente na competência geral da educação básica 7:

Argumentar com base em fatos, dados e informações confiáveis, para formular, negociar e defender ideias, pontos de vista e decisões comuns que respeitem e promovam os direitos humanos, a consciência socioambiental e o consumo responsável em âmbito local, regional e global, com posicionamento ético em relação ao cuidado de si mesmo, dos outros e do planeta. (Brasil, 2018, p. 9)

A argumentação no ensino médio pode ser trabalhada e estimulada numa proposta que coloca o estudante no centro do processo de aprendizagem, indo de encontro ao modelo da narrativa, criticado por Moreira (2010). Esse modelo clássico, muito presente na escola brasileira, ainda é pouco questionado pelos alunos, pelas famílias e até mesmo por professores, em que o ensino fica centrado no professor como uma figura detentora do conhecimento e que deve ser ouvida pelos seus aprendizes.

Nesse contexto, o estudo relatado neste artigo buscou explorar a experimentação investigativa como um meio de trabalhar a química do ensino médio, colocando o aluno no centro do processo de ensino-aprendizagem. Além disso, buscou-se investigar o quanto esse tipo de atividade poderia contribuir para que os alunos pudessem falar ciência, ou seja, expressarem seus conhecimentos químicos e resultados de experimentos de maneira mais lógica através de argumentos.

Na sequência será descrita uma breve revisão sobre a abordagem experimental escolhida para este estudo, a importância da argumentação no ensino de ciências, a metodologia do trabalho e seus resultados.

\section{Experimentação Investigativa}

O ensino por investigação consiste em uma abordagem didática que pode englobar diferentes estratégias, centradas no aluno. No contexto de aulas de ciências naturais, o ensino por investigação desperta a autonomia nos alunos e tem se destacado como uma abordagem que oportuniza a eles o contato com práticas científicas e epistêmicas que se aproximam do fazer científico (Jiménez-Aleixandre \& Crujeiras, 2017).

No trabalho com a experimentação investigativa há muitos elementos associados ao trabalho científico, porém o professor deve entender que o foco é a aprendizagem, não esperando que seus alunos venham a realizar descobertas (Azevedo, 2004).

O planejamento e posterior desenvolvimento de uma atividade experimental investigativa requerem, junto aos alunos: (a) um trabalho prévio com fundamentação teórica específica e contextualização do tema que se pretende explorar; (b) um trabalho prévio no laboratório (ou ambiente em que se pretenda desenvolver a experimentação), que vise à familiarização dos alunos com os equipamentos, vidrarias ou procedimentos experimentais; (c) iniciar a atividade principal de investigação a partir de uma pergunta - elaborada pelo aluno ou pelo professor; (d) possibilitar aos estudantes que desenvolvam a atividade, observem, anotem, elaborem hipóteses e as testem, refaçam o experimento na íntegra ou com adaptações - nesse caso, o professor deve ser consultado para avaliar se a adaptação é segura para ser conduzida; (e) haja um momento de socialização 
dos resultados entre os alunos de diferentes grupos e discussão geral para conclusões (Silva, 2011; Bianchini e Zuliani, 2009; Ferreira, Hartwig \& Oliveira, 2010).

Alunos envolvidos em atividades experimentais investigativas em laboratório de ciências mostram significativos ganhos como: habilidade de formular hipóteses, planejar e executar investigações, realizar minuciosas observações, coletar dados, analisar e interpretar variáveis e resultados, e sintetizar novos conhecimentos. Além disso, esse tipo de atividade pode promover curiosidade, criatividade, responsabilidade e satisfação (Raghubir, 1979). Assim, a experimentação investigativa faz com que os alunos, quando devidamente engajados, tenham um papel intelectual mais ativo durante as aulas, o que reflete diretamente na qualidade da aprendizagem.

Silva (2011), em sua dissertação de mestrado, investigou aspectos relacionados à elaboração de atividades experimentais investigativas. A partir disso, a autora propôs uma classificação em quatro níveis, de acordo com a proximidade à abordagem investigativa, a qual foi adotada para classificação das atividades utilizadas neste estudo e que serão detalhadas na metodologia. O Quadro 1 mostra os quatro níveis, de N1 a N4, e suas características.

Quadro 1 - Níveis de aproximação a uma atividade investigativa (Silva, 2011).

\begin{tabular}{|c|c|c|c|c|}
\hline \multirow{2}{*}{ Nível } & N1 & $\mathbf{N} 2$ & $\mathbf{N 3}$ & $\mathbf{N 4}$ \\
\hline & $\begin{array}{l}\text { Não apresenta } \\
\text { características } \\
\text { investigativas. }\end{array}$ & $\begin{array}{c}\text { Tangencia } \\
\text { características } \\
\text { investigativas. }\end{array}$ & $\begin{array}{c}\text { Apresenta algumas } \\
\text { características } \\
\text { investigativas. } \\
\end{array}$ & Atividade investigativa. \\
\hline Objetivo & $\begin{array}{l}\text { Tópicos a serem estudados } \\
\text { ou conteúdos específicos. }\end{array}$ & $\begin{array}{l}\text { Habilidades genéricas } \\
\text { e tópicos a serem } \\
\text { estudados. }\end{array}$ & $\begin{array}{l}\text { Habilidades e } \\
\text { competências } \\
\text { específicas. }\end{array}$ & $\begin{array}{c}\text { Habilidades e } \\
\text { competências específicas } \\
\text { relacionadas ao assunto } \\
\text { estudado. }\end{array}$ \\
\hline Problematização & Não apresenta. & $\begin{array}{c}\text { Questões sobre o } \\
\text { assunto estudado (com } \\
\text { o intuito de organizar } \\
\text { ou introduzir o assunto, } \\
\text { podem ou não ser } \\
\text { respondidas). }\end{array}$ & $\begin{array}{l}\text { Questões relacionadas } \\
\text { ao assunto estudado } \\
\text { que são retomadas } \\
\text { durante o experimento. }\end{array}$ & $\begin{array}{l}\text { Problema a ser resolvido } \\
\text { por meio da atividade } \\
\text { experimental, da busca de } \\
\text { informações e de } \\
\text { discussões. }\end{array}$ \\
\hline $\begin{array}{l}\text { Elaboração de } \\
\text { Hipóteses }\end{array}$ & Não há. & $\begin{array}{c}\text { Elaborada pelo aluno } \\
\text { para uma situação } \\
\text { específica que não é } \\
\text { explorada. }\end{array}$ & $\begin{array}{c}\text { Elaborada pelo aluno } \\
\text { para uma situação } \\
\text { específica que será } \\
\text { explorada na atividade. }\end{array}$ & $\begin{array}{c}\text { Elaborada pelo aluno a } \\
\text { partir da problematização. }\end{array}$ \\
\hline $\begin{array}{c}\text { Atividade } \\
\text { Experimental }\end{array}$ & $\begin{array}{c}\text { Experimento por } \\
\text { demonstração o aluno } \\
\text { observa o que o professor } \\
\text { apresenta sem interação. }\end{array}$ & $\begin{array}{l}\text { Experimento por } \\
\text { demonstração ou } \\
\text { realizado pelo aluno a } \\
\text { partir de um } \\
\text { procedimento dado. }\end{array}$ & $\begin{array}{l}\text { Experimento realizado } \\
\text { pelo aluno a partir de } \\
\text { um procedimento dado } \\
\text { com algum grau de } \\
\text { decisão no } \\
\text { procedimento. }\end{array}$ & $\begin{array}{l}\text { Experimento realizado } \\
\text { pelo aluno a partir de um } \\
\text { procedimento inicial e } \\
\text { completado ou sugerido } \\
\text { por ele. }\end{array}$ \\
\hline $\begin{array}{c}\text { Questões } \\
\text { Conceituais para os } \\
\text { Alunos }\end{array}$ & $\begin{array}{l}\text { Não exploram os dados } \\
\text { obtidos na atividade. }\end{array}$ & $\begin{array}{c}\text { Exploram parcialmente } \\
\text { os dados obtidos na } \\
\text { atividade prática, } \\
\text { solicitando ou não } \\
\text { conclusões parciais. }\end{array}$ & $\begin{array}{l}\text { Exploram os dados } \\
\text { obtidos na atividade } \\
\text { prática exigindo uma } \\
\text { conclusão. }\end{array}$ & $\begin{array}{c}\text { Exploram os dados } \\
\text { obtidos na atividade } \\
\text { prática exigindo uma } \\
\text { conclusão ou a aplicação } \\
\text { em novas situações. }\end{array}$ \\
\hline $\begin{array}{l}\text { Sistematização dos } \\
\text { Conceitos }\end{array}$ & $\begin{array}{l}\text { Realizada exclusivamente } \\
\text { pelo professor ou não } \\
\text { apresentada. }\end{array}$ & $\begin{array}{l}\text { Sem encaminhamento } \\
\text { de questões de análise } \\
\text { e de exploração da } \\
\text { hipótese. }\end{array}$ & $\begin{array}{l}\text { A partir dos resultados } \\
\text { das análises propostas } \\
\text { e exploração das } \\
\text { hipóteses. }\end{array}$ & $\begin{array}{l}\text { A partir das análises dos } \\
\text { resultados, do confronto } \\
\text { das ideias iniciais e finais, } \\
\text { da exploração das } \\
\text { hipóteses e das respostas } \\
\text { ao problema proposto. }\end{array}$ \\
\hline $\begin{array}{l}\text { Características do } \\
\text { Experimento }\end{array}$ & $\begin{array}{l}\text { Verificação ou ilustração de } \\
\text { conceitos. }\end{array}$ & $\begin{array}{c}\text { Apresenta } \\
\text { características de } \\
\text { verificação, porém com } \\
\text { uma exploração } \\
\text { conceitual inicial. }\end{array}$ & $\begin{array}{c}\text { Apresenta } \\
\text { características } \\
\text { investigativas devido } \\
\text { ao tipo de questões de } \\
\text { análise dos dados. }\end{array}$ & $\begin{array}{l}\text { Investigativo, busca } \\
\text { resolver o problema } \\
\text { proposto. }\end{array}$ \\
\hline
\end{tabular}

Fonte: Souza et al. (2013) 
Muitos autores tratam do que chamam de níveis de abertura para atividades experimentais investigativas, que se referem ao grau em que o problema de pesquisa, procedimentos e resultados são divulgados aos alunos antes da realização do experimento.

Tamir (1991) propôs a categorização da abertura desse tipo de atividade com o uso de um esquema de análise que leva em consideração a maior ou menor liberdade dos alunos nas escolhas e/ou desenvolvimento das seguintes áreas do processo experimental: (i) problemática a ser investigada, (ii) procedimentos experimentais, e (iii) dados e conclusões a partir desses.

O Quadro 2 ilustra isso de forma resumida, classificando a abertura de atividades experimentais investigativas em quatro níveis: de 0 a 3, que aqui serão representadas por A0 a A3, para não haver confusão com os níveis de argumentação que serão abordados posteriormente.

Quadro 2 - Níveis de abertura de atividades experimentais investigativas (Tamir, 1991)

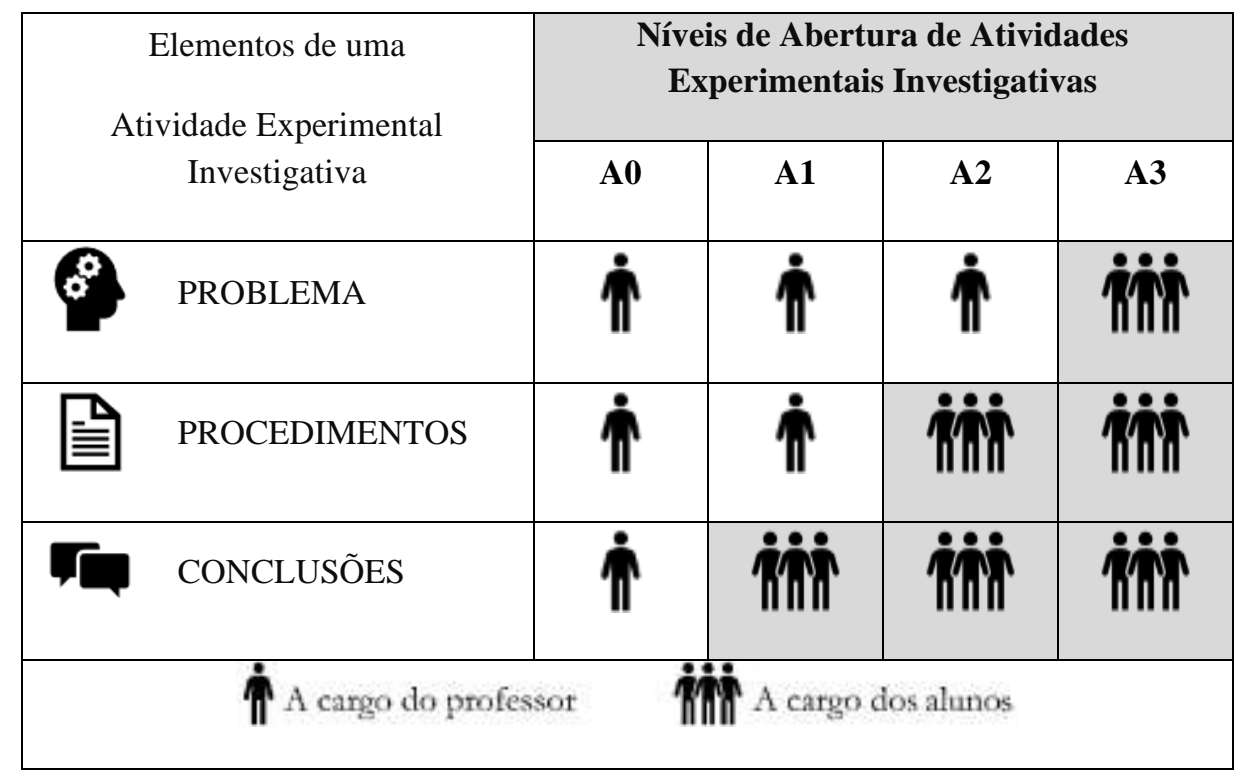

Fonte: Autoria própria (2021).

Para esse autor, as propostas de experimentos desenvolvidas numa abordagem puramente tradicional seriam análogas a um "livro de receitas", nos quais o problema, os procedimentos e as conclusões ficariam a cargo do professor. Nesse caso, seria baixo o nível de abertura da atividade. Já no outro extremo, de atividades experimentais abertas, as três áreas do processo de experimentação ficariam a cargo dos alunos.

Os graus mais abertos de experimentação investigativa rompem com o alto grau de memorização e dependência do professor, aumentam o grau de retenção dos assuntos abordados, facilitam a aplicação do que se aprende, além de abrir espaço para tomada de decisões e formulação de hipóteses (Gallet, 1998). Assim, Tamir (1991) propõe, acima de tudo, uma reflexão sobre o modo de se trabalhar a experimentação no ensino, objetivando maior motivação do aluno, o desenvolvimento de suas habilidades de investigação e realização, além de trabalhar parâmetros que são fundamentais para o método científico.

\section{Argumentação no Ensino de Ciências}

No Dictionnaire de l'argumentation (Plantin, 2016), a Ciência - química, física, biologia, medicina, etc - é reconhecida como um dos múltiplos domínios em que a argumentação é central. De fato, a argumentação e suas relacionadas 
refutações são elementos inerentes ao progresso da ciência e muitos pesquisadores têm se interessado em investigar os processos argumentativos na escola e na universidade, o que tem evidenciado o seu papel formador enquanto componente e meio para o ensino de conteúdos e de práticas epistêmicas, especialmente os científicos (Mirza \& Perret-Clermont, 2009; Jiménez-Aleixandre \& Erduran, 2008).

A linguagem científica é baseada em argumentos, portanto, aos alunos deve ser dada a oportunidade de falar ciência, que não significa falar sobre ciência, mas sim fazer ciência através da linguagem (Lemke, 1990), com benefícios como: desenvolvimento de compreensões conceituais e epistêmicas, construção de afirmações baseadas em evidências, desenvolvimento do pensamento crítico e de processos cognitivos de alta ordem, e desenvolvimento da autonomia; sendo esta última um dos objetivos mais importantes para a educação e, em particular, para a educação em ciências (Vieira \& Nascimento, 2013).

Além desses benefícios, as práticas argumentativas na escola são poderosas para promover maior interação:

É no intercurso de situações argumentativas que as interações entre os alunos, alunos e professor e alunos e materiais didáticos são favorecidas. Nessas múltiplas interações os alunos têm a oportunidade de emitirem e testarem hipóteses, avaliarem e construírem explicações e entendimentos sobre diferentes fenômenos que são debatidos durante investigações desencadeadas por situações-problemas a serem solucionadas (Ferraz \& Sasseron, 2017, p.3).

Na educação científica, as ferramentas mais conhecidas e comuns fornecidas pela teoria da argumentação são as analíticas desenvolvidas por Toulmin (2006), que têm sido usadas para melhorar os argumentos dos alunos e seus procedimentos interativos (Duschl, 2007). Essas pesquisas mostraram como os argumentos dos alunos, apoiados em predições sobre problemas científicos, podem revelar muito mais do que habilidades de raciocínio. Isso porque é possível analisar os diferentes componentes de seus argumentos.

O modelo de argumentação de Toulmin oferece uma caracterização mais estrutural à argumentação, que tem três componentes básicos: uma afirmação ou conclusão (C), dados (D) e justificativa ou garantia (G) (Toulmin, 2006). Os fatos ou dados (D) são as evidências usadas para provar uma afirmação ou conclusão (C). A garantia (G) é uma justificativa, que é de natureza hipotética e geral, tendo papel conector entre a evidência e a afirmação ou conclusão. Essas três partes são importantes para uma comunicação clara, principalmente quando se quer transmitir ideias e posicionamentos com convicção.

Em "Pedro nasceu em Porto Alegre, então ele deve ser gaúcho", a primeira parte da oração é a evidência (D) que dá suporte a afirmação de que Pedro é gaúcho (C). Nesse exemplo, a garantia ou justificativa está implícita, que seria: "Porto Alegre é uma cidade do Rio Grande do Sul e toda a pessoa nascida nesse estado brasileiro é gaúcha”. A justificativa, ausente no exemplo dado, é parte importante de um processo argumentativo, porém algumas vezes o orador assume que é óbvia demais para ser explicitada. No caso de processos argumentativos mais complexos em ensino-aprendizagem ou debates em que se objetiva a construção de uma conclusão sólida, o orador deve estar seguro da clareza de sua justificativa, a fim de que o ouvinte compreenda o porquê da defesa de tal ponto de vista, sem confusão ou má interpretação.

A Figura 1 mostra a estrutura do padrão proposto por Toulmin (2006), destacando o núcleo da argumentação contendo os três elementos básicos (D, G, C), anteriormente citados, bem como outros elementos que complementam esse núcleo, tornando o argumento mais rico. 
Figura 1 - Padrão de argumento, segundo Toulmin (2006)

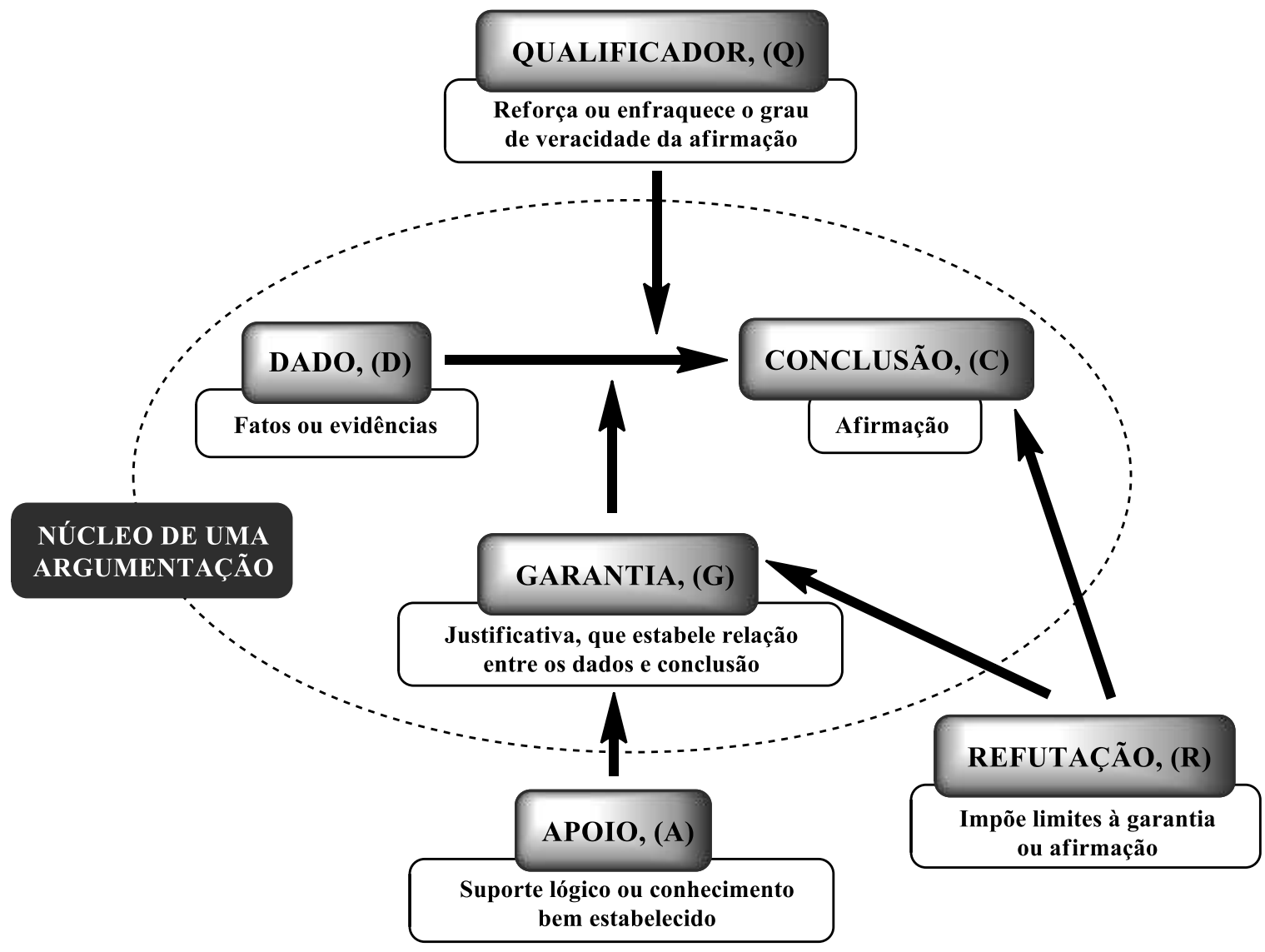

Fonte: Autoria própria (2021).

O apoio (A), refutação (R) e qualificador (Q) são aditivos que enriquecem o argumento, segundo o padrão de Toulmin. $\mathrm{O}$ apoio é um suporte lógico ou conhecimento bem estabelecido adicionado à justificativa, com intuito de melhor convencer a audiência. As refutações têm papel preventivo contra quaisquer contra-argumentos, evidenciando em quais situações a afirmação ou conclusão pode se tornar falsa e assim impondo limites à conclusão. Já os qualificadores modais são palavras ou expressões que qualificam a afirmação final no sentido de reforçá-la ou até mesmo enfraquecê-la. São exemplos de qualificadores: absolutamente, sempre, nunca, às vezes, geralmente, provavelmente.

Essa estrutura propõe um padrão para análise de argumentos a partir de elementos lógicos. A estrutura básica seria: $a$ partir de um dado $D$, já que $G$, então $C$.

Assim, o modelo de Toulmin pode ser considerado uma ferramenta para a compreensão da argumentação e suas relações com o pensamento científico, uma vez que uma das características de discursos nas ciências é a estima pela solidez de suas proposições (Capecchi \& Carvalho, 2004; Vieira \& Nascimento, 2013).

\section{Metodologia}

Neste trabalho, o caminho metodológico foi predominantemente qualitativo, o que permitiu a descrição do que foi estudado (Ludke \& André, 2013). Alguns itens foram analisados de forma quantitativa para evidenciar a magnitude dos fenômenos observados, principalmente para fins comparativos. 


\subsection{Sujeitos e contexto social da pesquisa}

A investigação foi desenvolvida com alunos do ensino médio regular de uma escola pública da rede federal no estado do Rio Grande do Sul entre os anos de 2014 e 2017. O curso de ensino médio dessa escola tem bastante prestígio na comunidade local, por seus resultados no ENEM.

O ingresso no ensino médio da escola ocorre por meio de seleção, que segue o sistema de cotas. Dessa forma, ingressam alunos oriundos do ensino fundamental de escolas públicas e particulares, com boa bagagem de conhecimento e com alto nível de motivação para estudar.

\subsection{Situação estudada}

O estudo foi conduzido em um laboratório de química da escola, com boa estrutura, equipamentos, vidrarias e reagentes. Nesse ambiente, cada atividade experimental foi desenvolvida com uma média de 12 alunos, que se reuniram em grupos menores de 3 ou 4.

As atividades aplicadas foram do tipo extraclasse e realizadas em turno inverso ao de aula normal. Os alunos já tinham familiaridade com atividades práticas no laboratório de química, conheciam questões de segurança, tinham experiência no manuseio de vidrarias, equipamentos e condução de práticas básicas, além de noções de tratamento e interpretação de dados de análises experimentais.

\subsection{Atividades experimentais do estudo e categorias para análise}

Foram trabalhadas 20 atividades experimentais investigativas, sendo que 18 delas foram elaboradas pelos autores e duas delas foram propostas pelos alunos. O estudo completo contemplou experimentos com variados assuntos de química das três séries do ensino médio e teve a participação de uma média entre 43 e 48 alunos por atividade.

As 20 atividades foram categorizadas em grupos, segundo os seguintes critérios:

@ ? nível de aproximação a uma atividade experimental investigativa (Silva, 2011): N1 a N4;

[? nível de abertura de uma atividade experimental investigativa (Tamir, 1991): A0 a A3.

Após classificação de cada atividade segundo os dois critérios, verificou-se que não havia atividade com grau de abertura A0. Então as atividades foram agrupadas em seis categorias, fruto da associação dos níveis $\mathrm{N}$ e A, no formato ( $\mathrm{Nx}$, Ay). A Figura 2 ilustra como as atividades foram categorizadas. 
Figura 2 - Esquema da categorização das 20 atividades experimentais investigativas.

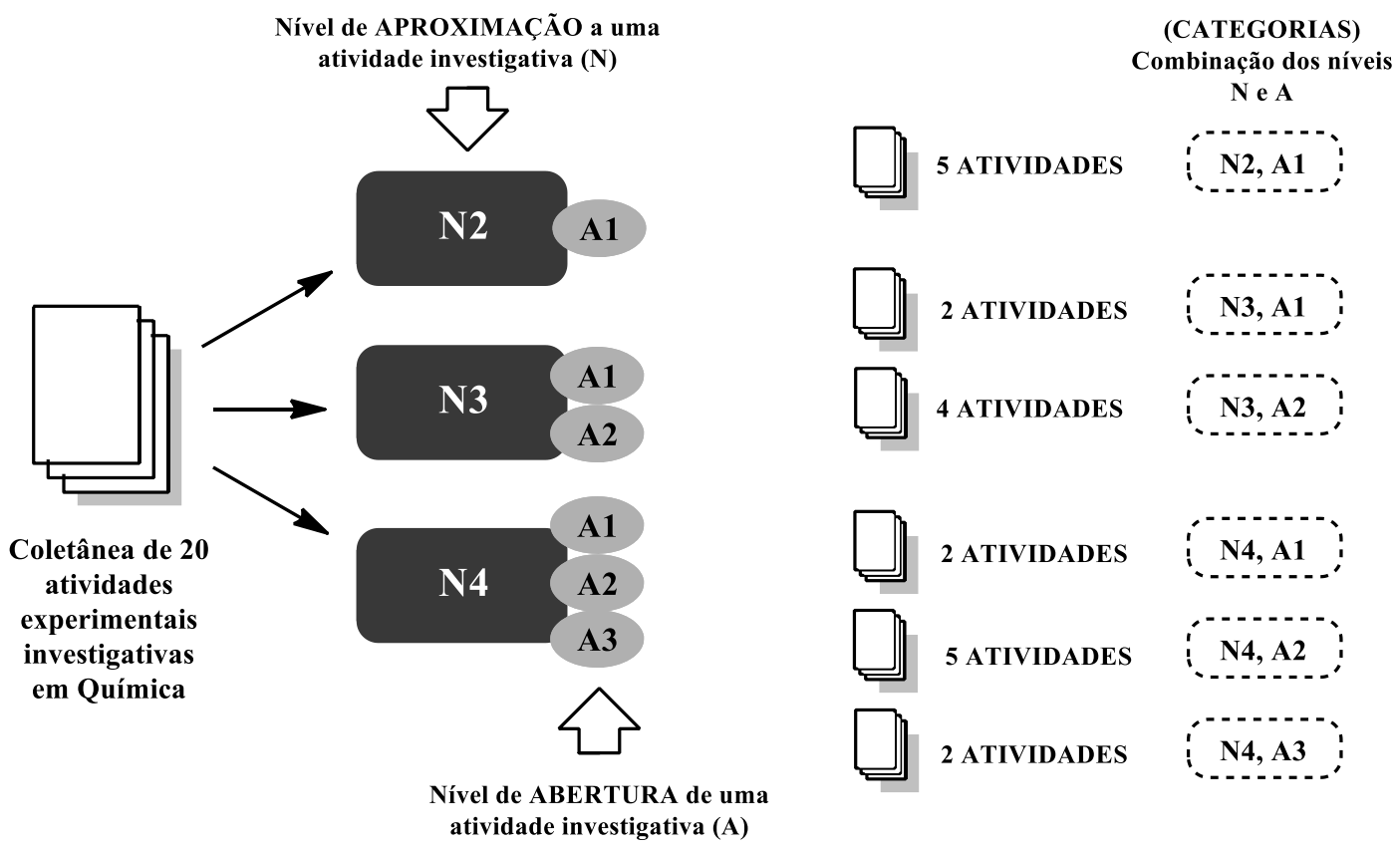

Fonte: autoria própria, 2021.

O Quadro 3 mostra a relação de atividades em suas categorias e a numeração, referente a ordem de aplicação em função da sequência de assuntos estudados no ensino médio. Cada atividade proposta tinha uma pergunta no título.

Quadro 3 - Relação de atividades experimentais investigativas e suas categorias.

\begin{tabular}{|c|c|}
\hline $\begin{array}{c}\text { Título da Atividade } \\
\text { Experimental }\end{array}$ & $\begin{array}{c}\text { Categoria da } \\
\text { Atividade }\end{array}$ \\
\hline Ativ 01 - É possível montar uma torre de líquidos? & $(\mathbf{N} 4, \mathbf{A} 2)$ \\
\hline Ativ 02 - Como separar tudo isso daqui? & $(\mathbf{N 4}, \mathrm{A} 2)$ \\
\hline Ativ 03 - Como se sabe se houve ou não reação química? & $(\mathrm{N} 3, \mathrm{A1})$ \\
\hline Ativ 04 - Por que a água tá fugindo? & $(\mathbf{N} 2, \mathbf{A 1})$ \\
\hline Ativ 05 - Como que $15 \mathrm{~mL}+15 \mathrm{~mL}$ não dá $30 \mathrm{~mL}$ ? & (N3, A2) \\
\hline Ativ 06 - Que gás é esse? Propriedades Químicas & (N3, A2) \\
\hline Ativ 07 - Algumas substâncias mudam de cor com o pH? & (N2, A1) \\
\hline Ativ 08 - Qual o pH desses produtos e alimentos? & $(\mathbf{N} 4, \mathbf{A 3})$ \\
\hline Ativ 09 - Estou coletando o volume correto? & $(\mathrm{N} 4, \mathrm{A1})$ \\
\hline Ativ 10 - Qual a concentração de ácido nessa amostra? & (N4, A1) \\
\hline Ativ 11 - Qual o teor de acidez desse vinagre? & $(\mathrm{N} 4, \mathrm{~A} 2)$ \\
\hline Ativ 12 - Uau! Como isso tá gelando sozinho? & (N3, A1) \\
\hline Ativ 13 - Quantas calorias tem esse alimento? & $(\mathbf{N} 4, \mathbf{A} 2)$ \\
\hline Ativ 14 - Pilha com limões e batatas? Como assim? & $(\mathrm{N} 4, \mathrm{~A} 2)$ \\
\hline Ativ 15 - Dá para acender lâmpadas com essas pilhas de limão? & $(\mathrm{N} 4, \mathrm{A3})$ \\
\hline
\end{tabular}


Research, Society and Development, v. 10, n. 16, e166101623540, 2021

(CC BY 4.0) | ISSN 2525-3409 | DOI: http://dx.doi.org/10.33448/rsd-v10i16.23540

\begin{tabular}{|l|l|}
\hline Ativ 16 - É possível decompor a água? & $\mathbf{( N 2 , \mathbf { A 1 } )}$ \\
\hline Ativ 17 - Cadê a cor que estava aqui? & $\mathbf{( N 2 , \mathbf { A 1 } )}$ \\
\hline Ativ 18 - Misturam ou não misturam? & $\mathbf{( N 3 , \mathbf { A 2 } )}$ \\
\hline Ativ 19 - Quanto de álcool tem nessa gasolina? & $\mathbf{( N 3 , \mathbf { A 2 } )}$ \\
\hline Ativ 20 - Uma reação que produz um espelho? & $\mathbf{( N 2 , \mathbf { A 1 } )}$ \\
\hline
\end{tabular}

Fonte: Autoria própria (2021).

$\mathrm{Na}$ última parte de cada atividade os grupos de alunos foram incentivados a apresentarem suas conclusões e a responderem perguntas do professor e dos colegas de outros grupos. Foi solicitado aos alunos que fizessem exposições orais $d a$ forma mais completa possivel, resgatando conhecimentos prévios do assunto, conhecimentos teóricos de aula, hipóteses iniciais, etc.

Nessa parte da aula foram analisadas as falas dos alunos, sendo que não foi realizada uma análise fina dos discursos, mas a observação atenta para a identificação e registro da ocorrência de argumentos e seus componentes, considerando o padrão de argumento de Toulmin (2006). Para tal análise foi utilizada uma ferramenta baseada nos autores: Erduran et al., 2004; Osborne et al., 2004; Simon \& Johnson, 2008. Nessa proposta, os argumentos são classificados em 5 níveis, AR1 a AR5, de acordo com os componentes do padrão de Toulmin presentes (Figura 3).

Figura 3 - Nivelamento do grau de argumentação, considerando o padrão de Toulmin. Metodologia de: Erduran et al., 2004;

Osborne et al., 2004; Simon e Johnson, 2008.

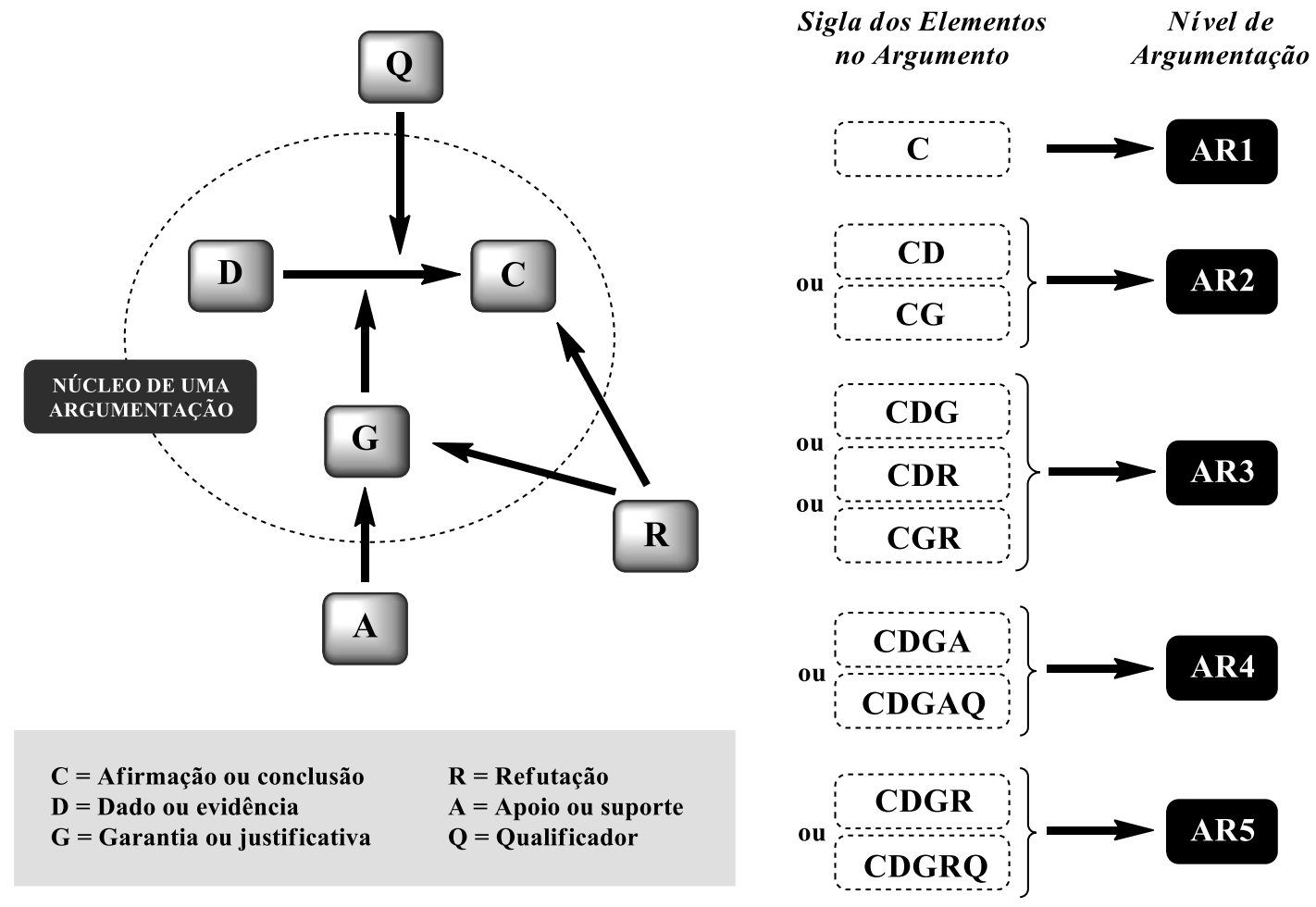

Fonte: Autoria própria (2021).

Essa ferramenta de nivelamento de argumentação foi escolhida por se alinhar com o tipo de discurso que surge em aulas experimentais (Erduran et al., 2004; Osborne et al., 2004; Simon \& Johnson, 2008.). 


\section{Resultados e Discussão}

O estudo desenvolvido foi uma forma de reinventar a experimentação que já era trabalhada no ensino médio da escola foco. A utilização da experimentação investigativa no laboratório de química mostrou-se rica e motivadora, tanto para o docente, como para os alunos. Houve casos de alguns estranharem a falta de roteiros mais tradicionais para certos experimentos, porém o notável engajamento nas atividades propostas foi algo muito positivo, que se refletiu nos diálogos mais presentes durante as aulas, com menor participação do professor.

A Figura 4 evidencia isso, mostrando a média do tempo de fala nas atividades propostas. Percebe-se que em todas as atividades houve predominância de discussões entre os alunos, sejam dentro de um mesmo grupo ou entre os grupos. Mas é notável a relação inversa entre o aumento do nível de investigação/abertura com a fala do professor nas atividades. Isso é um indicador positivo, quando se tem por objetivo a busca de uma educação centrada no aluno.

Figura 4 - Média do tempo de fala do professor e dos alunos nas atividades propostas.

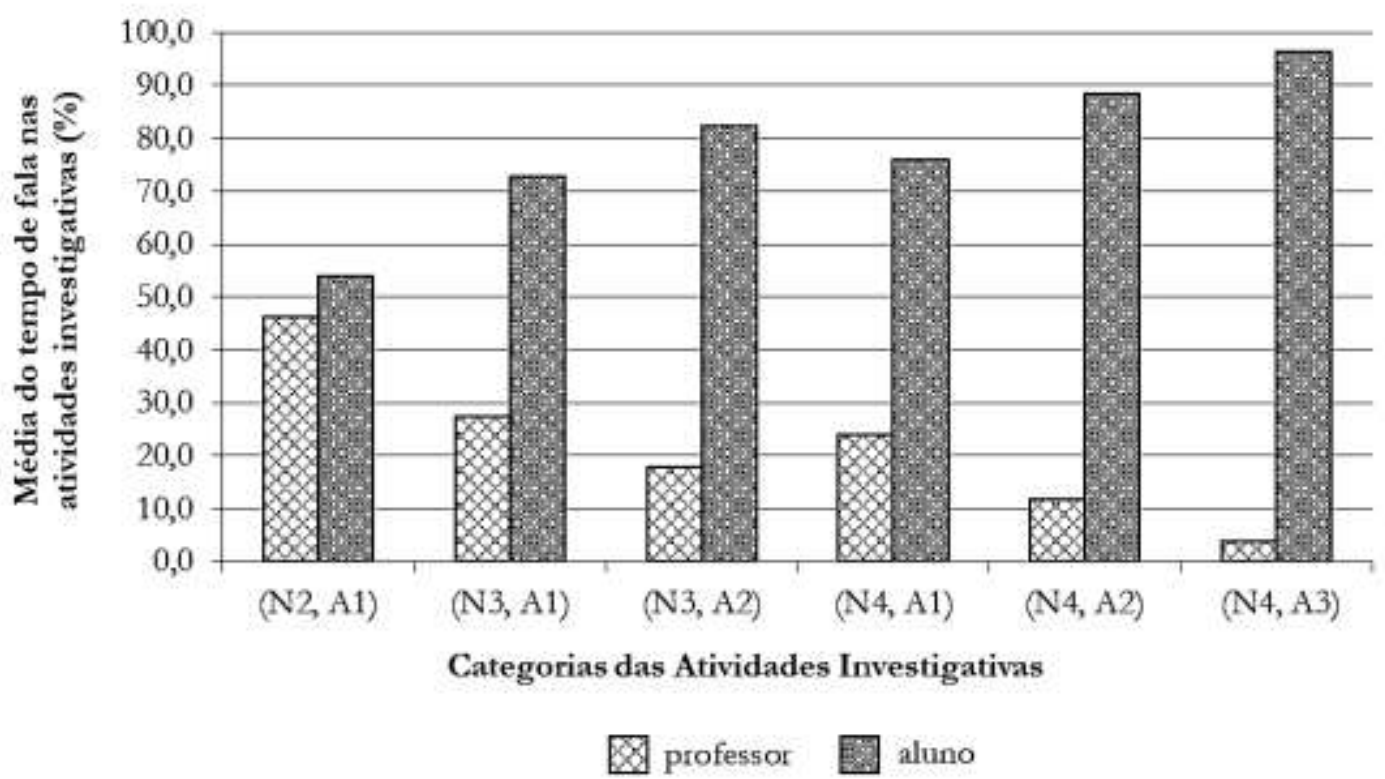

Fonte: Autoria própria a partir da pesquisa (2021).

O estudo revelou, além da participação mais ativa dos alunos nos experimentos, a presença de argumentos nos cinco níveis propostos na ferramenta de análise. Isso durante as discussões reservadas para o final das atividades.

O Quadro 4 traz um exemplo de argumento para cada nível (AR1 a AR5) proposto pela ferramenta de análise. Foram dados nomes fictícios para os alunos nesse quadro. 
Quadro 4 - Exemplos de argumentos, classificados em seus níveis de argumentação, segundo (Erduran et al., 2004; Osborne et al., 2004; Simon \& Johnson, 2008.).

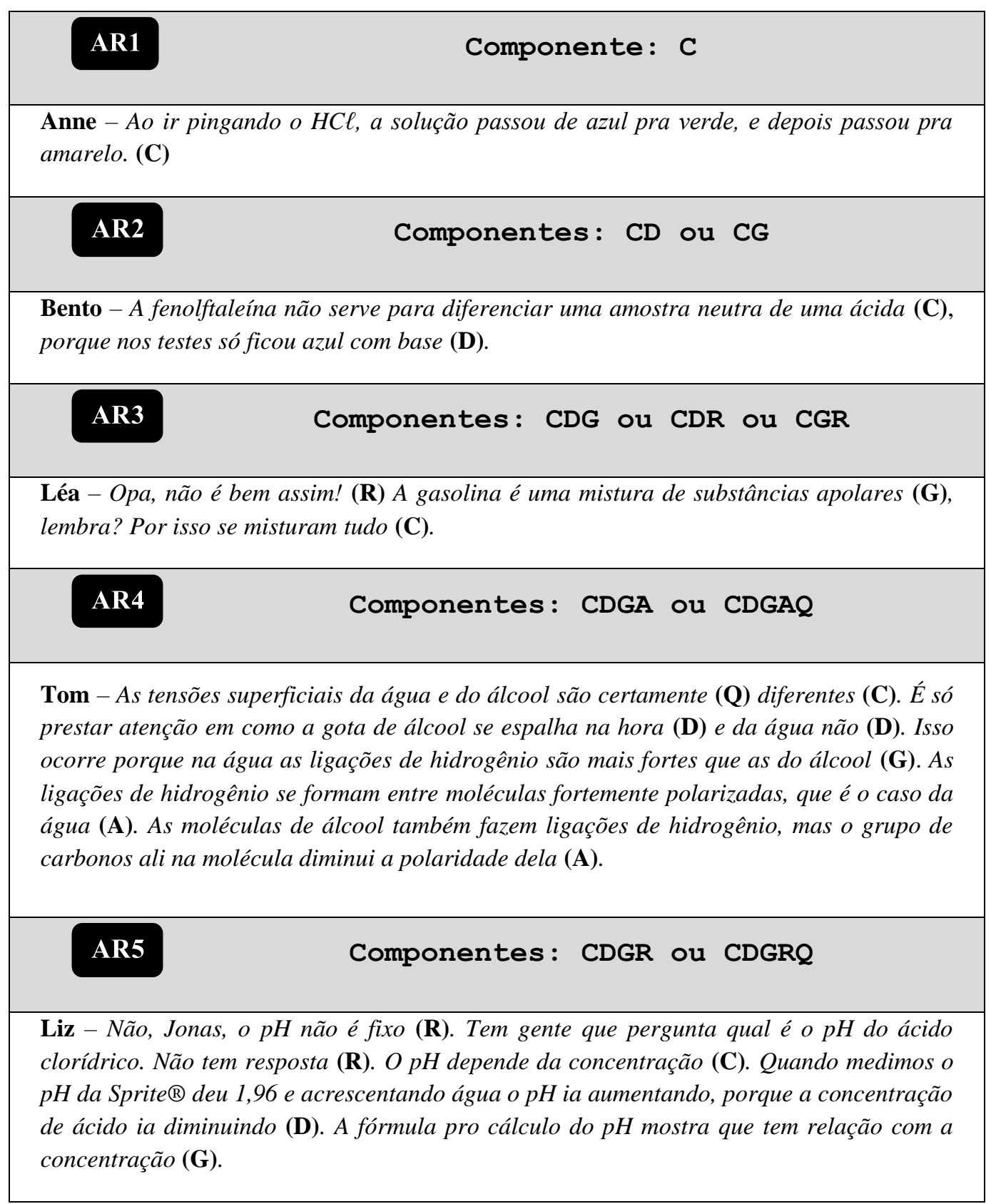

Fonte: Autoria própria a partir da pesquisa (2021).

Os níveis AR1 e AR2 são considerados para argumentos pobres, sem a utilização de justificativas, não contemplando os elementos mínimos do núcleo de argumentação do padrão de Toulmin. Por outro lado, um argumento de nível AR3 ou superior é mais completo, ficando ainda mais rico com a presença de refutação e outros elementos, como evidenciado nos exemplos. Esses argumentos de maior nível apresentam uma relação mais lógica entre suas partes, que podem apresentar-se em diferentes posições durante o discurso.

A Figura 5 refere-se aos dados da ocorrência de argumentos para as atividades da categoria (N2, A1), ou seja, a categoria com o menor grau de proximidade de uma atividade investigativa e menor grau de abertura. Percebe-se uma 
Research, Society and Development, v. 10, n. 16, e166101623540, 2021

(CC BY 4.0) | ISSN 2525-3409 | DOI: http://dx.doi.org/10.33448/rsd-v10i16.23540

predominância de argumentos fracos, níveis AR1 e AR2. Nota-se também a baixa presença de argumentos de nível AR4 em três das cinco atividades e ausência do nível AR5 em quatro das cinco atividades.

Figura 5 - Categoria (N2, A1) - Histogramas comparando o número absoluto de argumentos de diferentes níveis por atividade $(\mathrm{N}=121$ argumentos, referentes ao conjunto de 5 atividades $)$

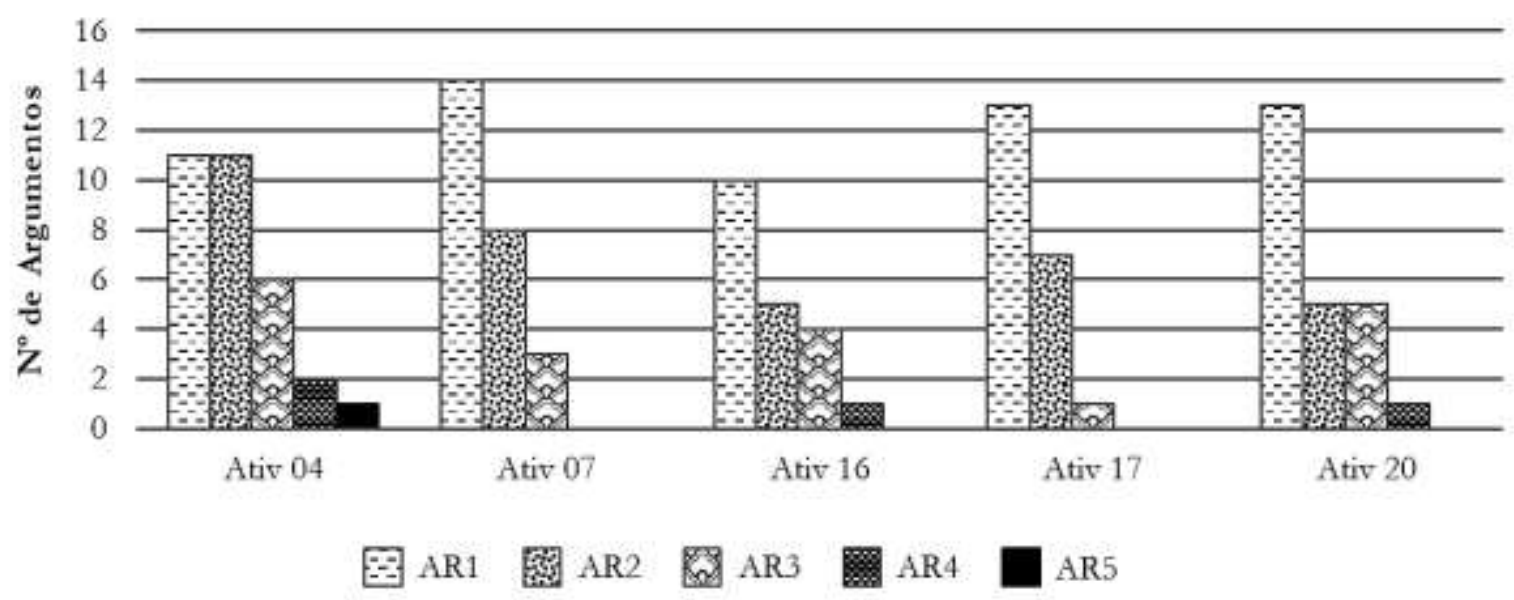

Fonte: Autoria própria a partir da pesquisa (2021).

Para a categoria (N3, A1), que apresenta um nível a mais de proximidade de atividade investigativa quando comparada à categoria anterior, ainda há predominância dos argumentos fracos de nível AR1 e nível AR2, porém um aumento nos argumentos AR3. Novamente há ausência de argumentos nível AR5 para uma das atividades.

Figura 6 - Categoria (N3, A1) - Histogramas comparando o número absoluto de argumentos de diferentes níveis por atividade ( $\mathrm{N}=75$ argumentos, referentes ao conjunto de 2 atividades)

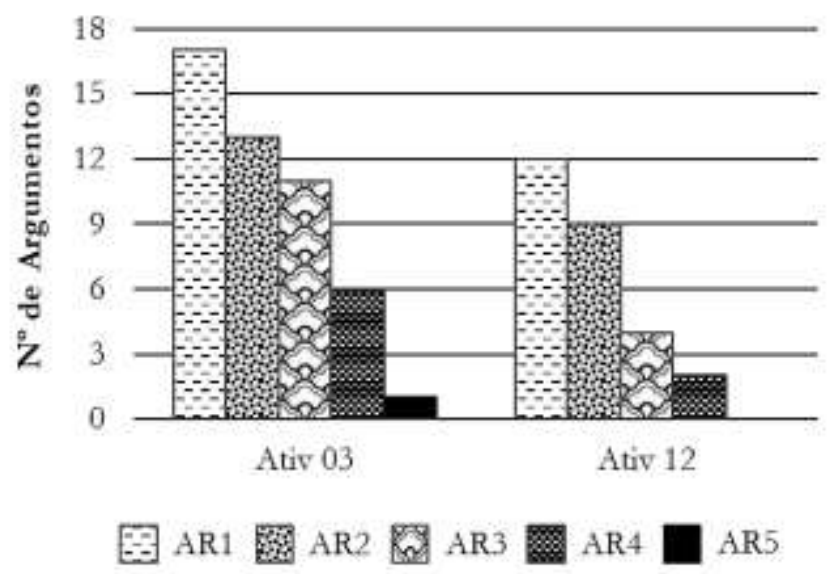

Fonte: Autoria própria a partir da pesquisa (2021).

A Figura 7 revela uma distribuição mais próxima para os argumentos dos níveis AR1 a AR4 para duas das quatro atividades. Nas outras duas, o nível AR1 superou os demais. Há aqui uma melhor distribuição de argumentos completos, AR3 ou superior. 
Figura 7 - Categoria (N3, A2) - Histogramas comparando o número absoluto de argumentos de diferentes níveis por atividade ( $\mathrm{N}=194$ argumentos, referentes ao conjunto de 5 atividades)

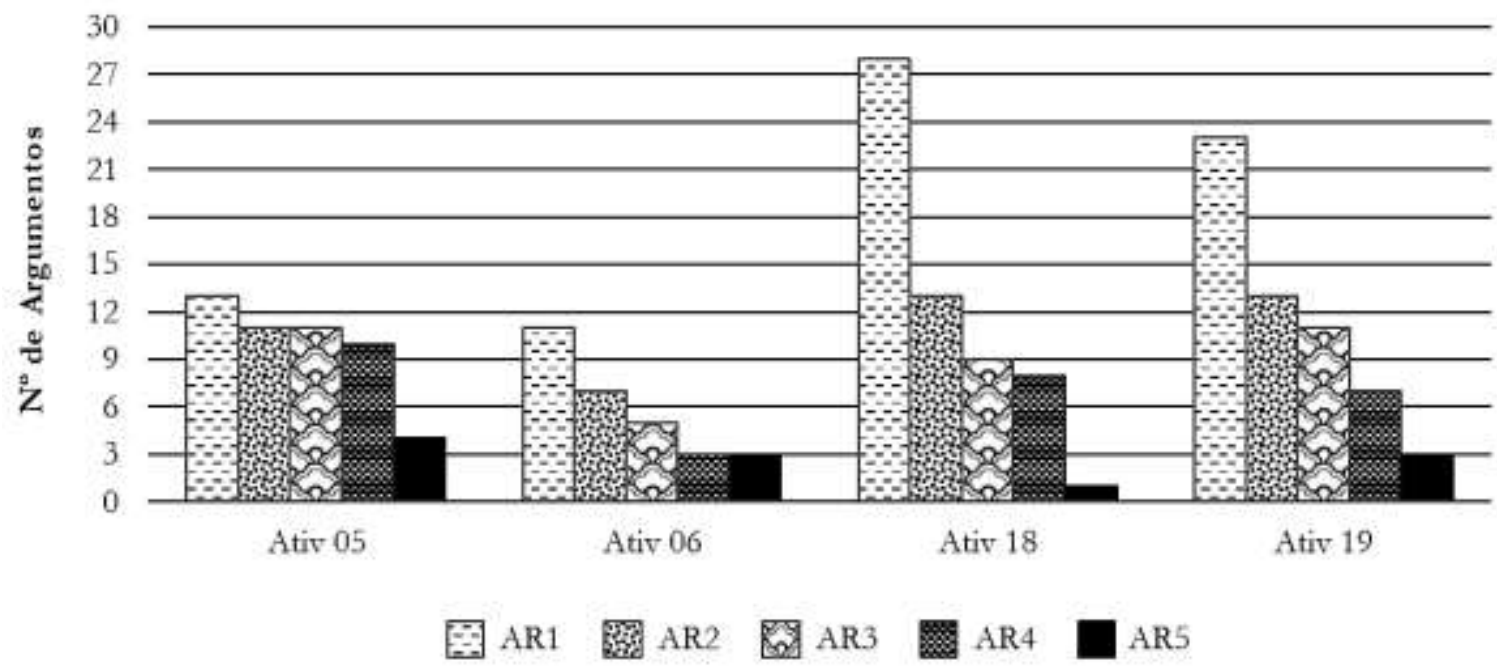

Fonte: Autoria própria a partir da pesquisa (2021).

A Figura 8 inicia a apresentação dos resultados para a categoria com o mais alto nível de aproximação à uma atividade investigativa, porém ela é mais fechada por ter deixado a cargo dos alunos somente a apresentação de conclusões, já que problemas e procedimentos foram fornecidos. A ocorrência de argumentos totais foi menor que na categoria anterior.

Figura 8 - Categoria (N4, A1) - Histogramas comparando o número absoluto de argumentos de diferentes níveis por atividade ( $\mathrm{N}=63$ argumentos, referentes ao conjunto de 2 atividades $)$

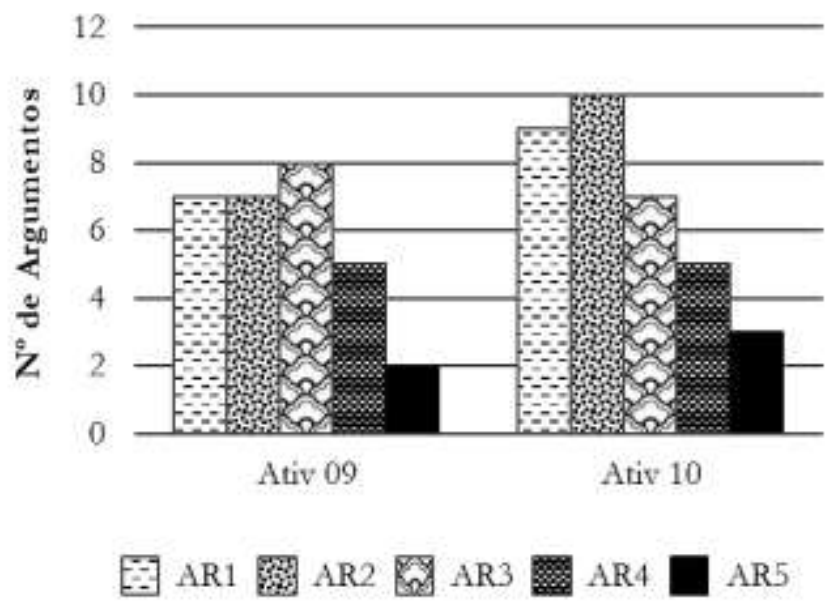

Fonte: Autoria própria a partir da pesquisa (2021).

A Figura 9 mostra, para a categoria (N4, A2), uma superação em número de argumentos bons (A3 ou superior), quando comparados aos argumentos de nível AR1 e AR2 dentro de uma mesma atividade. Nessa categoria estão incluídos experimentos que exigiram maior protagonismo dos alunos. Eles tiveram que planejar a investigação, coletar dados, testar hipóteses e buscar conclusões. O resultado disso foi a produção de discursos mais ricos em argumentos consistentes, pois além 
de conduzirem a experimentação, os alunos tiveram que defender suas metodologias e conclusões, necessitando para isso um maior embasamento na exposição oral. Assim, apareceram nos discursos um maior número de argumentos com suporte (apoio) às justificativas, além de refutações, que marcam argumentos de ordem superior.

Figura 9 - Categoria (N4, A2) - Histogramas comparando o número absoluto de argumentos de diferentes níveis por atividade ( $\mathrm{N}=131$ argumentos, referentes ao conjunto de 5 atividades)

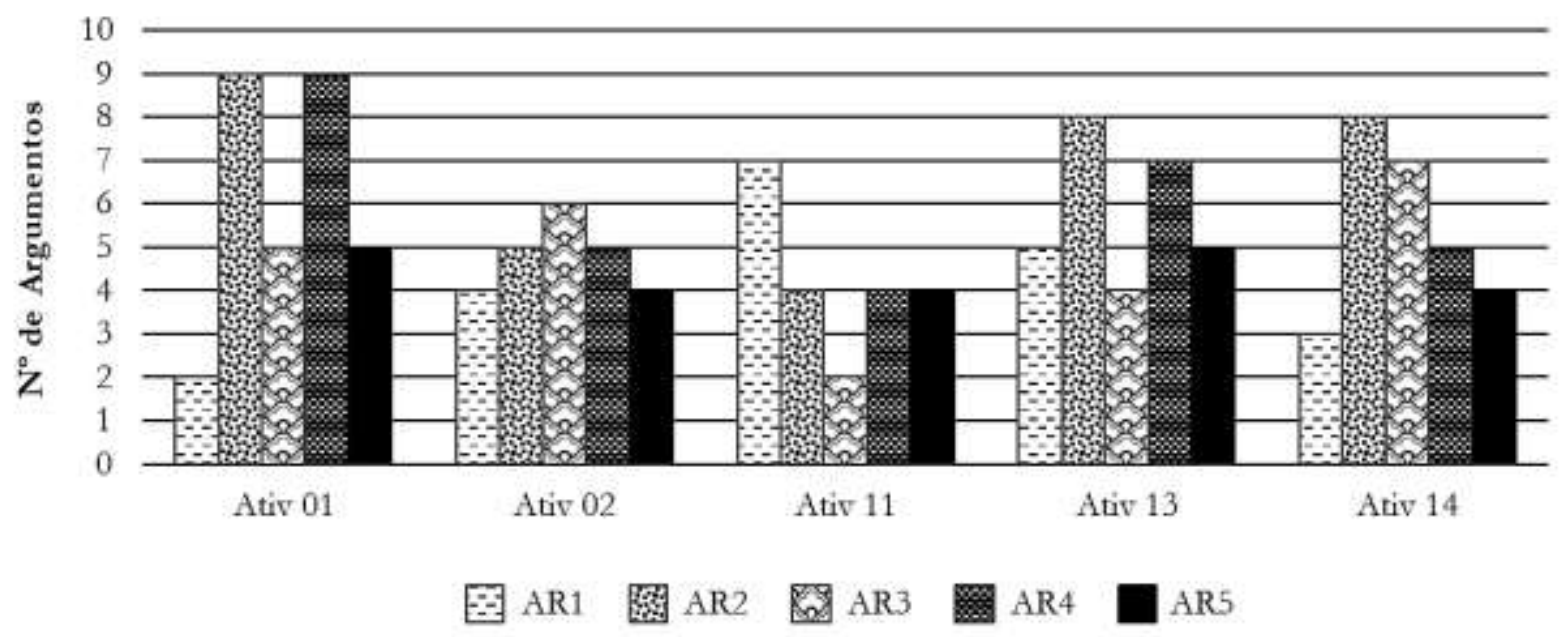

Fonte: Autoria própria a partir da pesquisa (2021).

Por fim, a Figura 10 traz os resultados da categoria com os dois experimentos sugeridos pelos próprios alunos (N4, A3). Essas atividades têm máximo grau de abertura e, assim como na categoria anterior, os alunos tiveram que planejar como conduziriam suas investigações e coleta de dados, além de propor conclusões claras e bem embasadas. Pela análise dos histogramas pode-se perceber que os considerados bons argumentos superaram, em número, os argumentos da categoria anterior. Vale ressaltar que nessas atividades os alunos estavam com grau de motivação maior, visto que a problemática a ser investigada tinha partido deles próprios. Isso impactou na intensidade das discussões no laboratório.

Figura 10 - Categoria (N4, A3) - Histogramas com o número absoluto de argumentos de diferentes níveis por atividade ( $\mathrm{N}=$ 91 argumentos, referentes ao conjunto de 2 atividades)

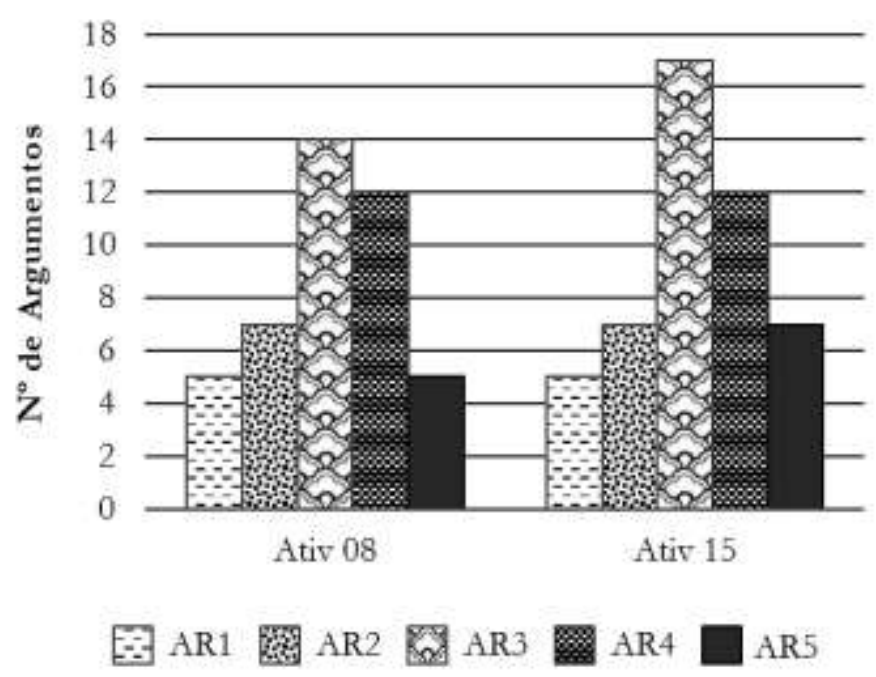

Fonte: Autoria própria a partir da pesquisa (2021). 
A Figura 11 mostra a frequência da ocorrência, agora em porcentagem, de argumentos AR1 a AR5 para as diferentes categorias.

Figura 11 - Frequência da ocorrência de argumentos, em \%, para as diferentes categorias

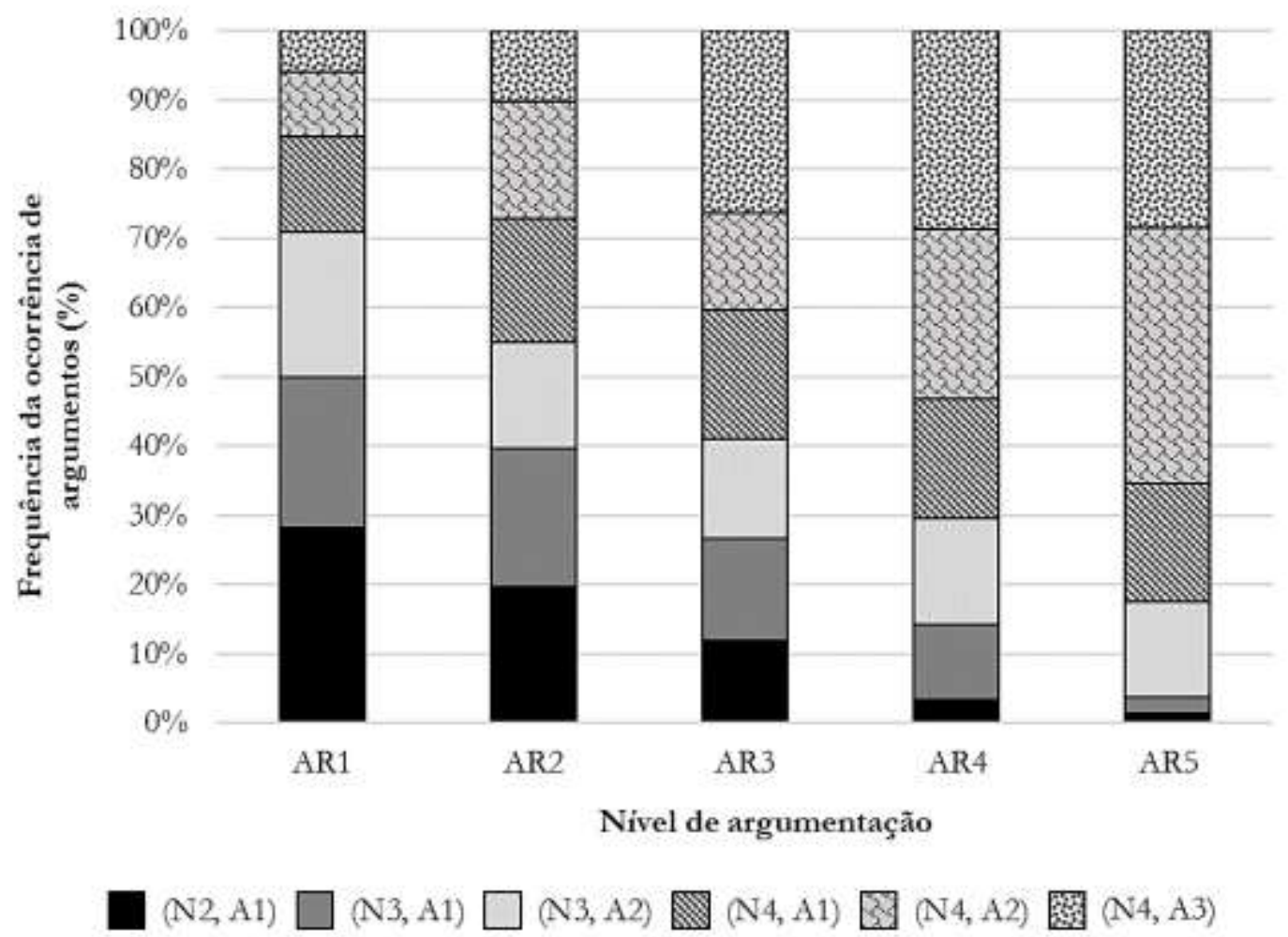

Fonte: Autoria própria a partir da pesquisa (2021).

Nessa figura, percebe-se que argumentos de menor nível, AR1 e AR2, são mais frequentes para as duas categorias com menores níveis de investigação e abertura. Já no outro extremo, percebe-se que argumentos AR4 e AR5 são mais frequentes para as categorias com maior nível de investigação e abertura.

\section{Considerações Finais}

A partir deste estudo, pôde-se constatar que o trabalho em laboratório de química com uma abordagem experimental investigativa prestou-se como uma boa plataforma para o exercício e desenvolvimento de habilidades argumentativas, que nesse contexto refere-se ao falar ciência.

Foi possível testemunhar os alunos motivados e engajados na busca comprometida pela resolução de problemas científicos. O sucesso disso em parte deveu-se a escolha de abordar conceitos simples nas atividades, porém importantes no estudo da química no ensino médio. Nesse sentido, foi comprovado que o simples é capaz de oferecer um caminho rico em aprendizagens, desde que bem conduzido e bem explorado.

O objetivo dessas atividades não era o de revelar cientistas, ou mesmo esperar por grandes descobertas. O importante foi que os alunos tiveram oportunidades de discussão e planejamento de tarefas científicas de forma colaborativa, construindo o próprio conhecimento de forma individual e/ou coletiva. Tiveram oportunidade de explorar técnicas experimentais clássicas e instrumentais no laboratório que, no segundo caso, evidenciaram o caráter moderno e interdisciplinar da química como 
ciência. O grau de envolvimento dos alunos com os experimentos, propiciado pelas características da experimentação investigativa, proporcionou a participação de todos no processo e no debate, situações em que foram apoiados ou não por seus argumentos, tudo de forma respeitosa, visando a construção coletiva.

Assim, percebeu-se que esses resultados também têm uma importância social significativa, que vai além das fronteiras da escola, ao impactar a vida dos alunos com o desenvolvimento do pensamento crítico e autonomia. Para futuros estudos, pode-se explorar melhor a metodologia abordada neste trabalho com tópicos interdisciplinares em ciências da natureza, indo ao encontro do que é proposto no novo ensino médio brasileiro com a BNCC.

\section{Referências}

Azevedo, M. C. P. S. (2004). Ensino por investigação: problematizando as atividades em sala de aula. In: Carvalho, A. M., P. (Org.). Ensino de Ciências: unindo a pesquisa e a prática. São Paulo: Thomson, 19-33.

Bianchini, T. B.; Zuliani, S. R. Q. A. (2009). A investigação orientada como instrumento para o ensino de eletroquímica. In: Encontro Nacional de Pesquisa em Educação em Ciências, 7, Florianópolis. Anais. UFSC, 1-12.

Brasil. Ministério da Educação. Secretaria de Educação Básica. (2018). Base nacional comum curricular: educação é a base. Brasília: MEC/SEB. http://basenacionalcomum.mec.gov.br/.

Capecchi, M. C. V. M.; Carvalho, A. M. P. (2004). Argumentação numa Aula de Física. In: Carvalho, A. M. P (org). Ensino de Ciências: Unindo a Pesquisa e a Prática. Ed. Thomson: São Paulo, SP.

Duschl, R. A.; Scweingruber, H. A.; Shouse, A. W. (2007). Taking Science to School: learning and teaching science in Grades K-8. Washington, DC: National Academies Press.

Erduran, S.; Simon, S.; Osborne, J. F. (2004). TAPping into argumentation: developments in the application of Toulmin's Argument Pattern for studying science discourse. Science Education, v.88, 915-933.

Ferraz, A. T.; Sasseron, L. H. (2017). Espaço interativo de argumentação colaborativa: condições criadas pelo professor para promover argumentação em aulas investigativas. Revista Ensaio, v. 19, e2658, 1-25.

Ferreira, L. H.; Hartwig, D. R.; Oliveira, R. C. (2010). Ensino experimental de química: uma abordagem investigativa contextualizada. Química Nova na Escola, São Paulo, v. 32, n. 2, 101-106.

Gallet, Christian. (1998). Problem solving teaching in the chemistry laboratory: leaving the cooks... Journal of Chemical Education, v.75, n.1, 72-77.

Jiménez-Aleixander, M.P.; Crujeiras, B. (2017). Epistemic Practices and Scientific Practices in Science Education. In: Taber, K.S e Akpan, B., Science Education: an International Course Companion, 69-80.

Jiménez-Aleixander, M. P.; Erduran, S. (2008). Argumentation in science education: An overview. In S. Erduran, M. P. Jiménez-Aleixander (Eds.), Argumentation in science education: Recent developments and future directions. Dordrecht: Springer.

Lemke, J. L. (1990). Talking science: Language, learning, and values. Norwood, ed. Ablex.

Ludke, M. \& André, M. E. D. A. (2013). Pesquisa em educação: abordagens qualitativas. São Paulo: E. P. U.

Mirza, N. M.; Perret-Clermont, A. N. (Eds). (2009). Argumentation and education: theoretical foundations and practices. Dordrecht, Heidelberg, London, New York: Springer.

Moreira, Marco Antônio. (2010) Abandono da narrativa, ensino centrado no aluno e aprender a aprender criticamente. http://www.if.ufrgs.br/ moreira/Abandonoport.pdf.

Osborne, J. F.; Erduran, S.; Simon, S. (2004). Enhancing the quality of argument in school science. Journal of Research in Science Teaching, v.41, 994-1020.

Plantin, C. (2016). Dictionnaire de l'argumentation. Une introduction conceptuelle aux études d'argumentation. Lyon: ENS Éditions.

Raghubir, K. P. (1979). Inquiry Teaching. Journal of Research in Science Teaching, 13-17.

Silva, D. P. (2011). Questões propostas no planejamento de atividades experimentais de natureza investigativa no ensino de química: reflexões de um grupo de professores. Dissertação de Mestrado - Universidade de São Paulo, Instituto de Física, Instituto de Química, Instituto de Biociências, Faculdade de Educação, São Paulo.

Simon, S.; Johnson, S. (2008). Professional learning portfolios for argumentation in school science. International Journal of Science Education, v.30, 669688 .

Souza, F. L.; Akahoshi, L. H.; Marcondes, M. E. R.; Carmo, M. P. (2013). Atividades experimentais investigativas no ensino de química. São Paulo: Centro Paula Souza. http://www.cpscetec.com.br/cpscetec/arquivos/quimica_atividades_experimentais.pdf. 
Research, Society and Development, v. 10, n. 16, e166101623540, 2021 (CC BY 4.0) | ISSN 2525-3409 | DOI: http://dx.doi.org/10.33448/rsd-v10i16.23540

Tamir, P. (1991). Pratical work at school: An analysis of current practice. In: Woolnough, B. (ed). Pratical Science. Milton Keynes: Open University Press.

Toulmin, S. (2006). Os usos do argumento. $2^{\mathrm{a}}$ ed. São Paulo: Martins Fontes, 2006.

Vieira, R. D.; Nascimento, S. S. (2013). Argumentação no Ensino de Ciências - Tendências, práticas e metodologia de análise. $1^{\mathrm{a}}$ Edição, Curitiba, Ed. Appris. 